\title{
EFFECT OF PARA-AMINOSALICYLIC ACID (PAS) ALONE AND IN ASSOCIATION WITH STREPTOMYCIN ON EXPERIMENTAL OCULAR TUBERCULOSIS*
}

\author{
BY \\ N. W. HORNE AND J. MACASKILL \\ Edinburgh
}

THE therapeutic effects of streptomycin and of para-aminosalicylic acid (PAS) in the control of many forms of experimentally induced tuberculosis and in the treatment of clinical tuberculosis are now well known. Although streptomycin is the most powerful antituberculosis drug which has so far been fully evaluated, evidence is accumulating that a combination of streptomycin and PAS is even more effective. (Karlson and Feldman, 1949; Medical Research Council, 1950). So far it has not proved possible to assess how much of this increased effect is due to the prevention of the emergence of streptomycin-resistant strains.

When this investigation was begun, we were unable to find any reference to the use of PAS alone or in combination with streptomycin in the treatment of experimentally induced or clinical tuberculosis of the eye. Several authors have since published their experiences in this field of investigation. Rees and Robson (1949) have shown that PAS had a definite beneficial effect on tuberculous infection of the cornea in rabbits, though it was less effective than streptomycin. In their experience a combination of streptomycin and PAS was more effective than either drug used alone. Rees and Robson (1950) recorded similar observations in tuberculous infection of the cornea in mice. Gardner and others (1949) found that PAS given by the intravitreous method was effective against tuberculous infection of the cornea of rabbits but much less so than streptomycin. Bietti (1950), using PAS and streptomycin separately and in combination in the treatment of experimental tuberculosis of the eye, noted that streptomycin was superior to PAS but that the best results were obtained by a combination of both drugs.

The present experiments were carried out with a view to determining whether PAS was an effective therapeutic agent in experimental ocular tuberculosis; and also whether when used in combination with streptomycin it enhanced the known beneficial effect of the latter.

Leopold and Nichols (1946) have shown that bacteriostatic levels of streptomycin can be obtained in the intra-ocular fluid of rabbits

* Received for publication March 22, 1951. 
by systemic administration. It seemed important also to determine whether PAS administered parenterally diffused into the intra-ocular fluids in a concentration sufficient to achieve a therapeutic level.

\section{EXPERIMENTS}

(1) Concentration of PAS in the Aqueous after Sub-conjunctival and Intramuscular Administration of the Drug in Rabbits.-PAS is known to be a substance which is rapidly absorbed and excreted. When given by mouth or parenterally appreciable concentrations of the drug are found in the blood and in the lung, liver, and kidney tissues. The drug diffuses into the cerebro-spinal fluid and the pleural cavity in low concentrations. When this investigation was begun we were unable to find any reference to the concentrations of PAS which could be obtained in the intra-ocular fluids. Since then, however, Witmer and Ragaz (1949) have recorded concentrations achieved after oral and sub-conjunctival administration, and Bietti (1950) has found therapeutic concentrations in rabbits after oral, intravenous, and intramuscular administration, and after iontophoresis of the cornea with a 5 per cent. solution of the sodium salt. Gardner and others (1949) have shown that the injection into the vitreous of $10 \mathrm{mg}$. sodium salt of PAS in a 10 per cent. solution produces a chemotherapeutic level of PAS within the eye for at least 48 hours. They comment, however, that when given by this route PAS produces toxic effects in the eye similar to or even greater than those produced by intravitreous streptomycin.

We investigated the concentration of PAS in the aqueous of rabbits following sub-conjunctival and intramuscular administration.

\section{(a) Sub-conjunctival Administration of PAS.}

METHOD.-Three rabbits of approximately the same weight $(2 \mathrm{~kg}$.) were selected. After instillation of 4 per cent. cocaine into the conjunctival sac, sub-conjunctival administration of a 30 per cent. solution of the sodium salt of PAS (Paramisan Sodium) was carried out in a dosage of $0.15 \mathrm{~g} . / \mathrm{kg}$. Half the dose-approximately $150 \mathrm{mg}$.was administered into each eye. At 30-minute intervals $0.2 \mathrm{ml}$. aqueous was withdrawn for estimation of the concentration, each eye being used once only. Readings were thus obtained at half-hourly intervals for a period of 3 hours. Blood samples were also taken at similar intervals. The concentrations of PAS were estimated by the method described by Newhouse and Klyne (1949), the intensity of colour being measured by a Hilger " Biochem " absorptiometer.

RESULTS.-The results of sub-conjunctival administration are shown in Fig. 1. The graph represents the average results of three such experiments. It will be seen that a very high concentration (over $20 \mathrm{mg}$. per cent.) was achieved within 30 minutes, and a therapeutic level was maintained for three hours. We are unable to explain the two peaks in the curve which occurred in each of the three experiments.

Very low concentrations of the drug (maximum $2.2 \mathrm{mg}$ per cent.) were obtained in the blood by this method of administration. No local illeffects were observed from the injection of the large amount of concentrated solution of PAS sub-conjunctivally. 


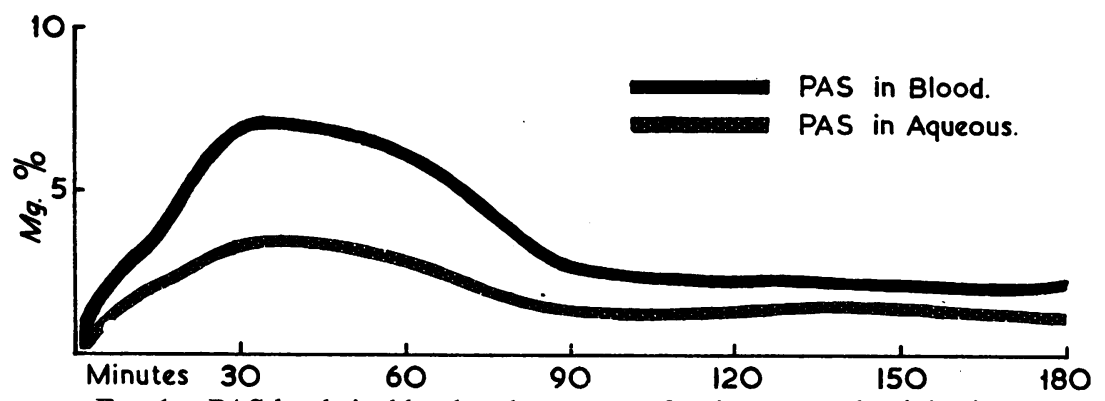

Fig. 1. PAS levels in blood and aqueous after intramuscular injection of $300 \mathrm{mg}$. PAS in rabbits of $2 \mathrm{~kg}$. weight.

(b) Intramuscular Administration of PAS.

METHOD.-Three rabbits of approximately $2 \mathrm{~kg}$. weight were given $150 \mathrm{mg}$. $/ \mathrm{kg}$. intramuscularly and estimations of the concentrations in the aqueous and in the blood were made in the same way as described above.

REsULTS.-The results shown in Fig. 2 represent the average of a series of three such experiments. The concentrations achieved in the aqueous are generally lower than those obtained in the blood. This was also recorded by Bietti (1950). Intramuscular injection of PAS in this dosage maintained a therapeutic concentration in the aqueous for probably less than 90 minutes, though small amounts (about $1.0 \mathrm{mg}$. per cent.) persisted for at least 3 hours.

Comparison of Figs 1 and 2 shows that sub-conjunctival administration gives a considerably greater concentration in the aqueous over a longer

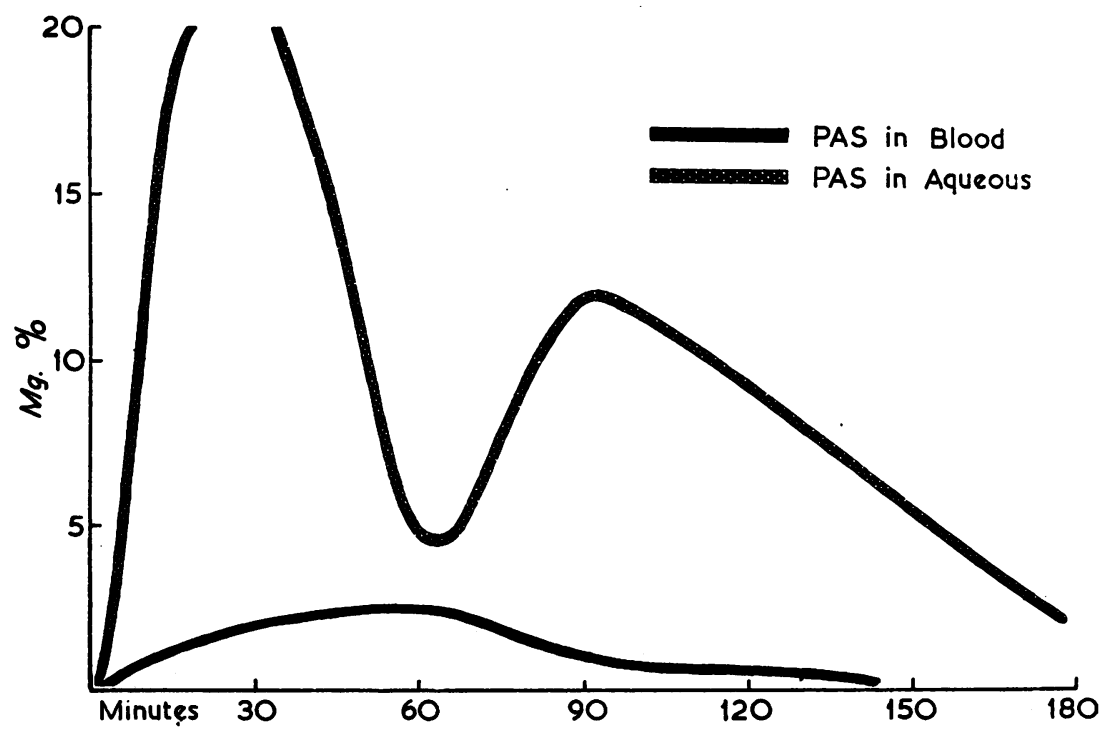

FIG. 2. PAS levels in blood and aqueous after sub-conjunctival injection of $150 \mathrm{mg}$. PAS in each eye of rabbits of $2 \mathrm{~kg}$. weight. 
period of time than intramuscular injection of the same amount. The daily sub-conjunctival injection of PAS however seemed to us to be an impracticable procedure. Witmer and Ragaz (1949) have recorded the maintenance of effective concentrations of PAS in the aqueous for several hours after the injection of as small a dose as $30 \mathrm{mg}$. sub-conjunctivally, and also comment that frequent injections are not practicable. Their observations and our own are in marked contrast with those of Bietti (1950) who records low concentrations in the aqueous (less than $0.5 \mathrm{mg}$. per cent. after one hour, $2.0 \mathrm{mg}$. per cent. after two hours) after subconjunctival injections of as much as $500 \mathrm{mg}$. sodium salt of PAS.

(2) Effect of PAS Alone and in Combination with Streptomycin in the Treatment of Tuberculous Ocular Lesions in the Rabbit.-Woods, Burky, and Friedenwald (1940), in their classical experiments on experimental ocular tuberculosis, have drawn attention to the differing course which this infection runs in the non-immune animal compared with one which has previously received tuberculous infection-the so-called "immuneallergic " animal. They have shown that the course of the disease is more restrained in the immune-allergic than in the normal animal. Consequently, if non-immune animals are used, the drugs under trial are subjected to a more severe test.

In these experiments non-immune rabbits were used.

The various methods of producing tuberculous lesions in the eye have recently been reviewed. We considered that the method described by Macaskill and Weatherall (1950) produced lesions which very closely resembled clinical tuberculosis of the eye and this method was used in the present experiments.

METHOD.-A strain of mycobacterium tuberculosis, human type C 37688, was used and the suspension made as in previous experiments (Macaskill and Weatherall, 1950). This was matched against standard opacity tubes and diluted until a suspension containing approximately 15,000 organisms per $\mathrm{ml}$. was produced.

Adult rabbits of approximately $2 \mathrm{~kg}$. weight were used. Inoculation was made into the anterior chamber under chloroform anaesthesia. The severity of the lesions produced was assessed by clinical examination of the eyes in life, by post-mortem search for dissemination of the infection, and by histological examination.

Sixteen rabbits were used and both eyes of each were inoculated with the suspension of tubercle bacilli. After 31 days, when nearly all eyes showed signs of infection, the rabbits were divided into four groups according to the severity of the lesions and, in each group of four, rabbits were allotted to different treatments by a random procedure. Treatment lasted 42 days and was as follows:

Group O. Controls.

Group S. Streptomycin in daily subcutaneous dosage of $60 \mathrm{mg}$. dissolved in $0.3 \mathrm{ml}$. distilled water.

Group P. PAS in daily intramuscular dosage of $1.5 \mathrm{ml} .20$ per cent. solution.

Group PS. Combined PAS and streptomycin in above dosage.

The severity of the lesions was regularly assessed for a period of 11 weeks after inoculation, the assessment being made by the method of scoring previously described (Macaskill and Weatherall, 1950), the observer being unaware of the treatment which the rabbit had received. Some had to be killed before the termination of the experiment. All animals were examined post mortem, and histological sections were made of the eyes, and of portions of lung, spleen, and kidney. 
Tuberculin Tests.-These were carried out by the intradermal method with 1 in 10 Old Tuberculin. By the 6th week all the animals showed mild positive tuberculin reactions.

RESUlTs.-After inoculation of the eyes with the suspension of tubercle bacilli, a transitory redness was seen which lasted 24 to 48 hours, and thereafter the eyes were white and quiet and undistinguishable from normal eyes. About the 22 nd day most of the eyes showed a mild iritis and a few days later minute centres of caseation appeared in the iris. These grew larger and in some cases later became confluent to form larger areas of caseation. In others, thinning and bulging at the corneo-scleral junction portended the extension of the disease to the outside of the eye.

The progress of the groups is shown in Fig. 3. For purposes of com-

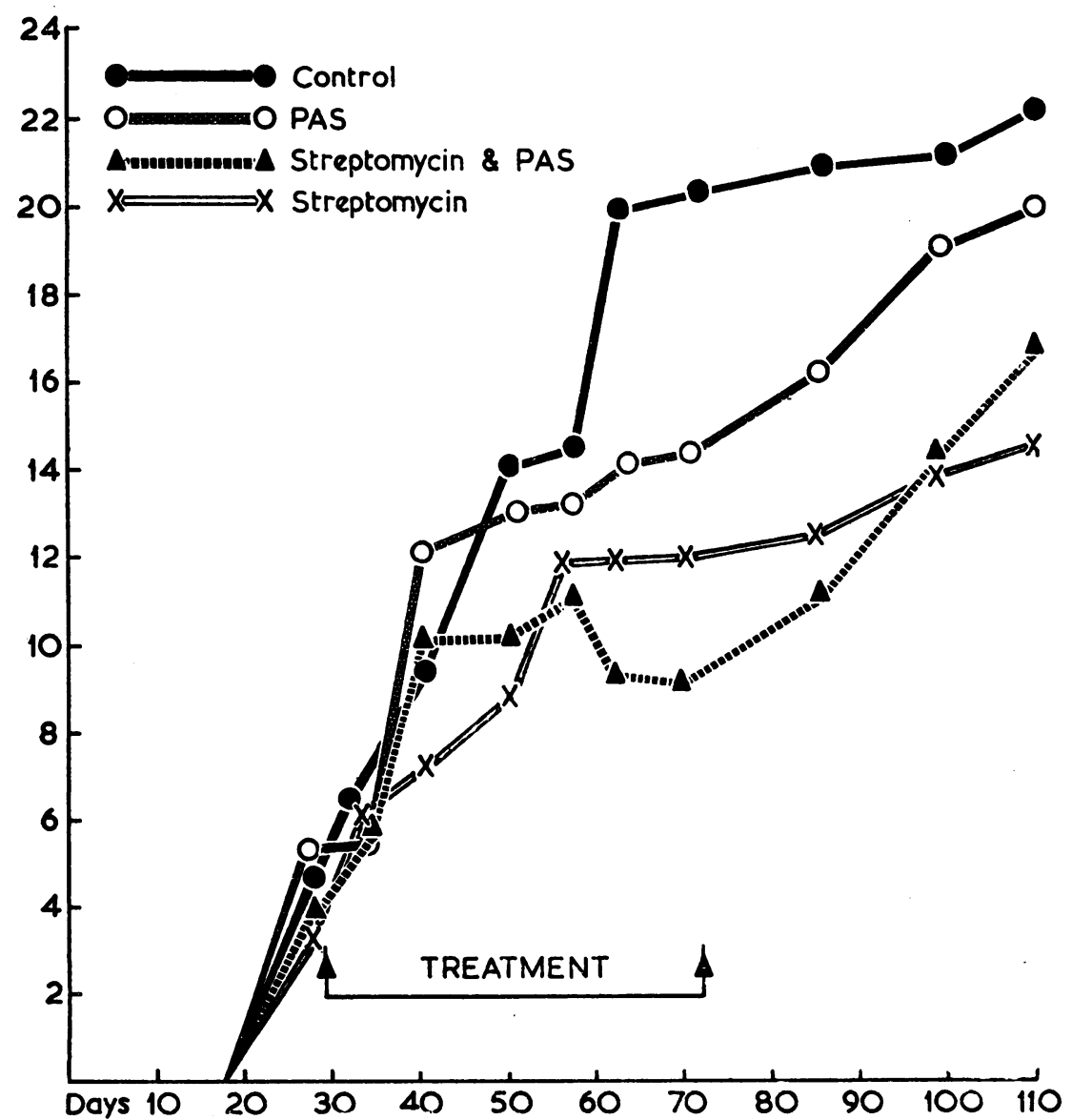

FIG. 3. Progress of the four separate groups under treatment. (The points on the left-hand scale represent an arbitrary assessment of the severity of the lesions). 
parison, the animals killed before the end of the experiment continued to be scored as immediately prior to death, which was considered fair as each group was affected. All treated groups did better than the control but that using PAS alone only slightly better. Both groups in which streptomycin was given were significantly better. During treatment, the combined group (PAS and streptomycin) appeared to do best, but after cessation of treatment worsening occurred so that the final result in the combined group was not so good as that in which streptomycin alone was used. The differences between the groups were equally observable during life and both macroscopically and histologically at death.

\section{MACROSCOPIC EXAMINATION}

The extent of the visceral lesions is shown in the following Table. When dissemination of tuberculous infection occurred, it was limited to the lungs. No macroscopic involvement of liver or spleen was observed.

The group treated by streptomycin showed no evidence of tuber-

TABLE

SEVERITY OF OCULAR AND DISSEMINATED LESIONS IN TREATED AND CONTROL GROUPS

\begin{tabular}{|c|c|c|c|c|c|c|c|c|c|}
\hline \multirow[b]{3}{*}{$\begin{array}{c}\text { Treatment } \\
\text { Group }\end{array}$} & \multirow[b]{3}{*}{$\begin{array}{c}\text { Rabbit } \\
\text { No. }\end{array}$} & \multicolumn{2}{|c|}{$\begin{array}{l}\text { Period of } \\
\text { Survival }\end{array}$} & \multicolumn{6}{|c|}{ Lesions (macroscopic) } \\
\hline & & \multirow[b]{2}{*}{$\begin{array}{l}\text { No. of } \\
\text { Days }\end{array}$} & \multirow[b]{2}{*}{ Average } & \multicolumn{2}{|c|}{ Eyes } & \multicolumn{2}{|c|}{ Lungs } & \multirow[b]{2}{*}{ Spleen } & \multirow[b]{2}{*}{ Liver } \\
\hline & & & & $\begin{array}{l}\text { Degree } \\
\text { of } \\
\text { Case- } \\
\text { ation } \\
(0-8)\end{array}$ & Average & $\begin{array}{c}\text { Degree } \\
\text { of } \\
\text { Case- } \\
\text { ation } \\
(0-3)\end{array}$ & Average & & \\
\hline Control & $\begin{array}{l}278 \\
279 \\
281 \\
282\end{array}$ & $\begin{array}{r}62 \\
53 \\
62 \\
112\end{array}$ & 74.8 & $\begin{array}{l}8 \\
3.12 \\
6 \\
5\end{array}$ & 5.53 & $\begin{array}{l}1 \\
1 \\
1 \\
1\end{array}$ & 1 & $\begin{array}{l}0 \\
0 \\
0 \\
0\end{array}$ & $\begin{array}{l}0 \\
0 \\
0 \\
0\end{array}$ \\
\hline PAS & $\begin{array}{l}271 \\
272 \\
277 \\
280\end{array}$ & $\begin{array}{r}112 \\
62 \\
53 \\
98\end{array}$ & 81.1 & $\begin{array}{l}5 \\
4 \\
5 \\
6\end{array}$ & 5 & $\begin{array}{l}3 \\
2 \\
1 \\
3\end{array}$ & 2.25 & $\begin{array}{l}0 \\
0 \\
0 \\
0\end{array}$ & $\begin{array}{l}0 \\
0 \\
0 \\
0\end{array}$ \\
\hline $\begin{array}{l}\text { Strepto- } \\
\text { mycin } \\
\text { and } \\
\text { PAS }\end{array}$ & $\begin{array}{l}266 \\
268 \\
273 \\
275\end{array}$ & $\begin{array}{r}53 \\
98 \\
112 \\
53\end{array}$ & 79 & $\begin{array}{l}2.75 \\
6 \\
4.5 \\
3.5\end{array}$ & 4.06 & $\begin{array}{l}0 \\
0 \\
1 . \\
0\end{array}$ & 0.25 & $\begin{array}{l}0 \\
0 \\
0 \\
0\end{array}$ & $\begin{array}{l}0 \\
0 \\
0 \\
0 .\end{array}$ \\
\hline $\begin{array}{c}\text { Strepto- } \\
\text { mycin }\end{array}$ & $\begin{array}{l}267 \\
269 \\
270 \\
276\end{array}$ & $\begin{array}{r}112 \\
53 \\
112 \\
62\end{array}$ & 84.8 & $\begin{array}{l}3.12 \\
3 \\
2.12 \\
6\end{array}$ & 3.56 & $\begin{array}{l}0 \\
0 \\
0 \\
0\end{array}$ & 0 & $\begin{array}{l}0 \\
0 \\
0 \\
0\end{array}$ & $\begin{array}{l}0 \\
0 \\
0 \\
0\end{array}$ \\
\hline
\end{tabular}


culosis in the lungs even although the average time of survival was greater than in the other groups. In the group treated with streptomycin and PAS one animal sacrificed on the 112th day showed several tuberculous foci in the lungs. In the control group disseminations were observed in all four animals, even in two killed on the 53rd day. All four animals in the PAS-treated group also showed dissemination into the lungs. The lesions were severe and broncho-pneumonic in type in three animals.

\section{HisTOPATHOLOGY}

Microscopic examination of the lungs subsequently confirmed the necropsy findings. All four animals in the control group showed the presence of large isolated areas of subacute caseating disease with some aggregation of epithelioid cells and slight evidence of a fibroblastic reaction. By contrast, the animals treated with streptomycin showed no histological changes apart from scanty perivascular and peribronchial lymphocyte collections and a very few minute areas of histiocyte aggregations. Of the animals treated with combined streptomycin and PAS, three showed changes similar to those in the streptomycin-treated group. The fourth animal however-which was killed at the end of the experiment on the 112th dayshowed extensive caseation with little epithelioid reaction and no tendency to healing. In contrast to the other treated groups, all four animals treated with PAS showed widespread areas of confluent caseation, these areas being surrounded by masses of epithelioid cells.

One small acute epithelioid tubercle was observed in the spleen of two of the control animals.

It will be seen that the degree of disseminated disease in the lungs was least in the streptomycin-treated group, the combined group faring rather less well on account of the single animal showing extensive disease. Both these groups fared considerably better than the control group. By contrast, the PAS-treated group showed extensive florid disease of a degree much more severe than that seen in the controls.

The numbers of tubercle bacilli observed in sections stained by the Ziehl-Neelsen method were very much greater in the PAS-treated animals than in the control group.

Although the number of animals in each group is small, the observations made in those treated with PAS are of interest in the light of a recent report by Levaditi and others (1949), who observed two distinct phases in the pathology of the lesions in mice inoculated with tubercle bacilli and treated with PAS. The first tentative healing was followed by a second stage in which 
recrudescence of the disease and appearance of numerous organisms occurred. These workers suggested that the most likely hypothesis to account for their findings was that the body's natural resistance to tubercle bacilli is lowered by prolonged PAS administration.

\section{SUMMARY}

(1) Observations are recorded on the concentration of paraaminosalicylic acid (PAS) which can be produced in the intraocular fluid in rabbits following sub-conjunctival and intramuscular injection.

(2) The effect upon experimentally produced tuberculous infection of the iris and ciliary body of PAS alone and in conjunction with streptomycin are recorded. All treated groups fared better than the controls. In the dosage used by us, PAS appeared to have little beneficial effect, and no significant enhancement of the effect of streptomycin was observed.

(3) In the PAS-treated group, the disseminated lung lesions were much more severe, and showed more numerous tubercle bacilli, than the other treated groups and the controls.

The expenses of this investigation were defrayed by the W. H. Ross Foundation (Scotland) for the Prevention of Blindness, for whose help we are most grateful. We wish to thank Professor Charles Cameron for his willing help and advice and for providing facilities at the laboratory at Southfield Sanatorium. Professor Murray Drennan of the Department of Pathology kindly reported on the histological sections and provided laboratory assistance in their preparation. We are indebted to Dr. J. R. Duguid of the Bacteriology Department for the suspension of tubercle bacilli used. Mr. David Hay gave us invaluable technical assistance.

\section{REFERENCES}

BIETti, G. B. (1950). Arch. Ophthal., Chicago, 43, 431.

Gardiner, P. A., Rees, R. J. W., and Robson, J. M. (1949). Brit. J. Pharmacol., 4, 209.

Karlson, A. G., and Feldman, W. H. (1949). Proc. Mayo Clin., 24, 510.

LeOPOLd, I. H., and Nichols, A. (1946). Arch. Ophthal., Chicago, 35, 33.

Levaditi, C., Vaisman, A., and Lévy, P. (1949). C.R. Soc. Biol., Paris, 143, 1432.

MACASKILl, J., and Weatherall, M. (1950). British Journal of Ophthalmology, 34, 147.

Medical Research Council (1950). Brit. med. J., 2, 1073.

Newhouse, J. P., and KLYNe, W. (1949). Biochem. J., 44, Proc. vii.

ReEs, R. J. W., and Robson, J. M. (1949). Nature, Lond., 164, 351. (1950). Brit. J. Pharmucol., 5, 77.

WitMer, R., and RAGAz, L. (1949). Schweiz med. Wschr., 79, 452.

WoOds, A. C., Burky, E. L., and FriedenWald, J. S. (1940). Arch. Ophthal., Chicago, 23, 351 . 